\title{
The Science and Art of Integrating the Mind and Body in Clinical Social Work
}

\author{
Terry B. Northcut $\cdot$ Rebecca J. Strauss
}

Published online: 12 June 2014

(c) Springer Science+Business Media New York 2014

We live in a world of dichotomies: right or wrong; left or right; guilty or innocent; science or art; mind or body. As we have discovered through the influence of postmodern philosophy, there are times when the answer often does not lie in an either/or perspective but rather in the discreet confluence of both. Certainly this is true with understanding how the mind and body interact to facilitate our efforts towards health and growth, as well as our ability to cope with trauma and loss. This special edition of the Clinical Social Work Journal is devoted to the rationale and the variety of ways in which mind and body can be integrated in clinical social work. Subjective and objective evidence suggests that integrating mind and body in clinical practice is materializing as a viable and enduring practice for helping both clients and clinicians maintain healthy and adaptive functioning. Philosophers, healers, midwives, scholars, artists, physicians, social workers, and psychotherapists have long known that the mind and body are connected in profound ways, yet the pendulum of treatment has swung back and forth between where the emphasis is placed. Depending on sociological, cultural, and economic factors surrounding care for the "patient" or "the one who suffers" (Merriam-Webster's online dictionary, 2014), clinical practice has often been placed on either side of the mind/body continuum, rather than exploring the symbiotic relationship between the two.

\footnotetext{
T. B. Northcut $(\bowtie)$

Loyola University of Chicago SSW, 820 N. Michigan Ave., Chicago, IL 60611, USA

e-mail: tnorthc@luc.edu

R. J. Strauss

Turning Point Behavioral Health, 8324 Skokie Blvd., Skokie, IL 60077, USA

e-mail: rstrauss@tpoint.org
}

One of our profession's greatest strengths is our ability to draw from both science and art to understand the mind/ body continuum by utilizing what science has discovered and also the freedom to incorporate creative innovation to help us help others. Chekov reminds us that "there is nothing new in art except talent." The authors in this special issue bring their talent, their knowledge, and their experience to the mind/body discussion to help us synthesize what we know, with what we continue to learn from our clients and our own self-care. One of the most frequent applications of integrating mind and body to ease one's suffering is the practice of mindfulness. "Mindfulness" is a term that seems to have reached a ubiquitous level of awareness, yet it remains a vague, often misunderstood concept in its application in everyday life and clinical practice. Each of the authors included in this special edition has explored these and other questions, and kindly share thoughts and clinical expertise with us based on his or her experience in the field.

As guest editors of this special edition, we envision this issue as a scholarly presentation of integrating mind/body elements in both micro and macro clinical social work practices. Our intention is to provide novice and seasoned clinicians, social work students, educators, and administrators with concrete means to step into this emerging focus of practice. A historical and didactic discussion of mindfulness is offered to bridge the gap between the origins of mindfulness practices in the Buddhist tradition, and the current secular applications in the field of clinical social work. This discussion blends psychodynamic principles of attachment theory and empathic response with mindfulness-based work to help individuals and couples move towards recovery. Findings from neuroscience reinforce the relevance of integrating the mind and body in ways that help clients navigate their own internal change process, and 
in ways they can understand and embrace on the intellectual, somatic, and emotional level. Case studies provide mind, body, and spiritual tools to further enhance direct social work practice, and ultimately empower clients with economical and accessible means for building their capacity for self-regulation, distress tolerance, and interpersonal effectiveness. This special edition also includes evidence-based research supporting this developing practice in the field of traumatic grief, with thought given to other clinically appropriate applications.

One approach to understanding the potential of mind/ body interventions is to examine our bias towards the Western concept of health that prioritizes "the absence of suffering" as a valid goal of psychotherapy. Through a Buddhist formulation and its associated practice of mindfulness meditation, Fulton encourages readers to look at the notion of suffering from a different lens, considering a state of well-being that is broader than the absence of symptoms and less bound by conditions. Fulton suggests the Buddhist framework may offer a transtheoretical and transcultural model of suffering and its treatment paradigms, allowing us to move beyond the "either/or approach of being sick or well," to allow for a more enhanced understanding of human potential.

Baldini, Parker, Nelson, and Siegel build on Siegel's ongoing work (Siegel 2010a, b; 2012a, b) and craft the idea of "clinician as neuroarchitect." By integrating aspects of the mind, attachment history, and interpersonal neurobiology, clients can be helped to move from an internal experience of chaos and rigidity to an internal capacity for stability and flexibility.

Physical and mental health relies heavily on the perception of the self as viable, strong, competent, and futureoriented. However when one's health is confronted with serious illness, this perception of self is compromised, often leaving one in a state of profound vulnerability. Strauss and Northcut demonstrate how integrating mind and body through conscious breathing, meditation, and yoga may help clients regain a felt sense of efficacy and empowerment as demonstrated in Strauss's clinical work with a young woman of child bearing age in the midst of cancer treatment.

For survivors of trauma, the dissociation that enables survival from the terror often transmutes to a general loss of control over physical sensations and emotions as they arise. Feeling anything in the body can be experienced as dangerous and threatening, leaving trauma survivors in an ongoing state of hyperarousal, unable to distinguish between a real or perceived threat. As Duros and Crowley poignantly state, sustainable recovery comes from systematically inviting the body to come to therapy too, within the safe and supportive framework of the Collaborative Change Model developed by Barrett (2013).
Northcut and Kienow place PTSD in the context of military culture and describe how the inherent need for loyalty and following orders, creates an easy target environment for sexual abuse of both male and female soldiers. Survivors of military sexual trauma (MST) contend with not only a loss of professional and personal identity, but also retraumatization that may occur when health and mental health service providers are part of the system that enabled the trauma.

Thieleman, Cacciatore, and Hill share a quasi-experimental study on the ATTEND model (Cacciatore 2011), a mindfulness-based treatment approach for traumatically bereaved adults faced with the untimely death of a child. Taking it one step further, Cacciatore, Thieleman, Osborn, and Orlowski present additional case material, supporting the integration of mind and body in the treatment of traumatic grief using the ATTEND model.

Judith Siegel extends mind/body connection to her work with couples. She demonstrates how couples are intrapsychically connected as their pasts are always present in their current relationship, often resulting in patterns of communicating that leave one or both partners without adequate resources for problem solving or getting mutual needs met without conflict. As one partner reacts by shouting, name calling, or other disruptive behaviors, Siegel suggests intervening on the somatic level with breathing exercises to not only calm affective experiences, but to allow one's cognitive skills to engage in a way that two-way communication becomes possible.

For guest editor Strauss, integrating mind and body through yoga, while cultivating self-awareness and attention through meditation practices, resulted in a career change into the field of clinical social work in 2010. While researching the academic curriculum in graduate level programs in her region of the country, she was disappointed in the dearth of academic offerings to support integrating mind and body in clinical settings. Raheim and Lu developed such a course and discuss the development, implementation, and outcomes of an elective MSW course that was designed to critically examine the IntegrativeMind-Body-Spirit (IMBS) practice and compare it to biomedical paradigms. Martinez bridges academia and clinical practice by challenging us to expand our theoretical framework to allow for clinical tools that capture the mind/ body continuum. The author suggests Berlin's CognitiveIntegrative Perspective (2002) provides a such a framework, allowing for a reflective understanding and application of mind/body/spirit that is consistent with social work values and what we currently know about the underlying science of mind.

Raney ends this special issue with an unusual plea for clinical social workers and those in the administration of social service agencies to consider addressing administrative 
concerns from a place of mindful observation, moving towards the challenges, and paying close attention to the moment-by-moment experiences to achieve agility in adversity. Raney reminds us that practice does not occur in a vacuum, and we must extend our ideas about integrating the mind and body to the actual systems that house the clinical work.

We thank each of these authors for taking the time to provide scholarly and pragmatic manuscripts on how they integrate mind and body in their clinical work. It is our hope that readers of Clinical Social Work Journal will give thought to this emerging frontier of care and explore new ways of connecting through a mindful presence in the therapeutic relationship and when appropriate, bring the body to therapy, too.

\section{References}

Barrett, M. J. (2013). Treating complex trauma: A relational blueprint for collaboration and change. New York: Rutledge.

Berlin, S. (2002). Clinical social work practice: A cognitiveintegrative practice. Oxford, NY: Oxford University Press.

Cacciatore, J. (2011). ATTEND: Toward a patient-centered model of psychosocial care. In C. Y. Spong (Ed.), Stillbirth: Prediction, prevention, and management ( $\mathrm{pp}$. 203-228). Oxford: Wiley Blackwell Publishing.
Patient. (2014). Retrieved May 27, 2014. http://www.merriamwebster.com/dictionary/patient.

Siegel, D. J. (2010a). The mindful therapist: A clinician's guide to mindsight and neural integration. New York: W.W. Norton \& Company.

Siegel, D. J. (2010b). Mindsight: The new science of personal transformation. New York: Bantam.

Siegel, D. J. (2012a). The developing mind, second edition: How relationships and the brain interact to shape who we are. New York: Guilford Press.

Siegel, D. J. (2012b). Pocket guide to interpersonal neurobiology: An integrative handbook of the mind. New York: W.W. Norton \& Company.

Terry B. Northcut, Ph.D., L.C.S.W. is an associate professor at Loyola University Chicago School of Social Work. Publications and scholarly interests include: integration of psychodynamic theory and cognitive-behavioral techniques, religion \& spirituality in psychotherapy, and mental health for children and families in Ethiopia. Dr. Northcut co-edited with Dr. Nina Heller "Enhancing psychodynamic practice with cognitive-behavioral techniques" and is currently working on a second book of that topic. Her mental health practice includes psychotherapy with adults, supervision, and consultation.

Rebecca J. Strauss, L.S.W., R.Y.T. received her MSW from Loyola University Chicago School of Social Work. Ms. Strauss is currently a psychotherapist at Turning Point Behavioral Health in Skokie, IL, integrating mindfulness practices in her mental health work with individuals and groups. Ms. Strauss is a registered yoga teacher and facilitates Mindful Stress Management workshops for adolescents and adults. 